\title{
Real-Time Optical Diagnosis of Colorectal Polyps in the Routine Clinical Practice Using the NICE and WASP Classifications in a Nonacademic Setting
}

\author{
Joana Castela ${ }^{a}$ Susana Mão de Ferro ${ }^{a}$ Isadora Rosa ${ }^{a}$ Pedro Lage ${ }^{a}$ \\ Sara Ferreira ${ }^{a}$ João Pereira Silva ${ }^{a}$ João Cortez Pinto ${ }^{a}$ Rita Vale Rodrigues $^{a}$ \\ Joana Moleiro $^{\mathrm{a}} \quad$ Isabel Claro ${ }^{\mathrm{a}}$ Susana Esteves ${ }^{\mathrm{b}}$ António Dias Pereira ${ }^{\mathrm{a}}$ \\ a Department of Gastroenterology, Instituto Português de Oncologia de Lisboa Francisco Gentil, E.P.E., Lisbon, \\ Portugal; ${ }^{b}$ Clinical Research Unit, Instituto Português de Oncologia de Lisboa Francisco Gentil, E.P.E., Lisbon, \\ Portugal
}

\section{Keywords \\ Colorectal polyps · Narrow-band imaging · Optical diagnosis · Learning effect}

\section{Abstract}

Background: Narrow-band imaging (NBI) allows "in vivo" classification of colorectal polyps. Objectives: We evaluated the optical diagnosis by nonexpert community-based endoscopists in routine clinical practice, the impact of training, and whether the endoscopists could achieve the threshold for the "do not resect" policy. Methods: This was an observational study performed in two periods (P1 and P2). Endoscopists had no prior experience in NBI in P1 and applied the technique on a daily basis for 1 year before participation in P2. Lesions were classified by applying the NBI International Colorectal Endoscopic (NICE) and Workgroup serrAted polypS and Polyposis (WASP) classifications, simultaneously. Results: A total of 290 polyps were analyzed. The overall accuracy of optical diagnosis was $0.75(95 \% \mathrm{Cl} 0.68-0.81)$ in P1, with an increase to $0.82(95 \% \mathrm{Cl} 0.73-0.89)$ in $\mathrm{P} 2(p=0.260)$. The accuracy of the NICE/WASP classifications to differentiate adenomatous from nonadenomatous histology was 0.78 (95\% Cl $0.72-0.84)$ in $\mathrm{P} 1$ and $0.86(95 \% \mathrm{Cl} 0.77-0.92)$ in $\mathrm{P} 2$ $(p=0.164)$; assignments made with a high confidence level achieved statistical significance (13\% improvement, $95 \% \mathrm{Cl}$ $3-22 \% ; p=0.022$ ). The negative predictive value for adenomatous histology of diminutive rectosigmoid polyps was $81 \%(95 \% \mathrm{Cl} 64-93 \%)$ and $80 \%(95 \% \mathrm{Cl} 59-93 \%)$ in $\mathrm{P} 1$ and P2, respectively. Conclusions: Nonexpert endoscopists achieved moderate accuracy for real-time optical diagnosis of colorectal lesions with the NICE/WASP classifications. The overall performance of the endoscopists improved after sustained use of optical diagnosis, but did not achieve the standards for the implementation of the "do not resect" strategy.

(c) 2019 Sociedade Portuguesa de Gastrenterologia Published by S. Karger AG, Basel

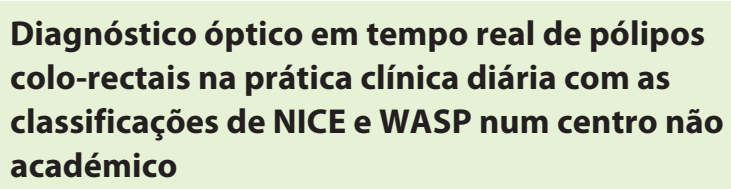

Palavras Chave

Pólipos colo-rectais · Narrow-band imaging · Diagnóstico óptico $\cdot$ Curva de aprendizagem

\section{KARGER}

E-Mail karger@karger.com www.karger.com/pjg
(C) 2019 Sociedade Portuguesa de Gastrenterologia Published by S. Karger AG, Basel

Karcer

Open access

This article is licensed under the Creative Commons AttributionNonCommercial-NoDerivatives 4.0 International License (CC BYNC-ND) (http://www.karger.com/Services/OpenAccessLicense). Usage and distribution for commercial purposes as well as any distribution of modified material requires written permission.
Dr. Joana Castela

Department of Gastroenterology

Instituto Português de Oncologia de Lisboa Francisco Gentil, E.P.E.

Rua Prof. Lima Basto, PT-1099-023 Lisbon (Portugal)

E-Mail joanarocastela@gmail.com 


\section{Resumo}

Introdução: O narrow-band imaging (NBI) permite a classificação "in-vivo" dos pólipos colo-rectais. Objectivos: Avaliámos o diagnóstico óptico na prática clínica diária em endoscopistas da comunidade, sem experiência prévia em NBI, o impacto do treino e se estes conseguiam atingir o limiar da estratégia de "não ressecar". Métodos: Estudo observacional, realizado em dois períodos (P1 e $\mathrm{P} 2$ ). Os endoscopistas não apresentavam experiência prévia em NBI em P1 e aplicaram a técnica diariamente durante um ano antes da participação em P2. As lesões foram classificadas aplicando as classificações NBI International Colorectal Endoscopic (NICE) e Workgroup serrAted polypS and Polyposis (WASP), simultaneamente. Resultados: Foram analisados 290 pólipos. A acuidade global do diagnóstico óptico foi de 0.75 (IC 95\%, 0.68-0.81) em P1, aumentando para 0.82 (IC 95\%, 0.73-0.89) em P2 ( $p=$ 0.260). A acuidade das classificações de NICE/WASP na diferenciação de histologia adenomatosa de não-adenomatosa foi de 0.78 (IC 95\%, 0.72-0.84) em P1, e 0.86 (IC $95 \%, 0.77-0.92)$ em P2 ( $p=0.164)$; as predições realizadas com alto grau de confiança alcançaram significado estatístico (melhoria de 13\%, IC 95\%, 3-22\%; $p=0.022$ ). 0 valor preditivo negativo para histologia adenomatosa dos pólipos diminutos recto-sigmóides foi de $81 \%$ (IC 95\%, 64-93\%) e 80\% (IC 95\%, 59-93\%), em P1 e P2, respetivamente. Conclusões: Endoscopistas sem experiência em NBI alcançaram acuidade moderada no diagnóstico óptico em tempo real de lesões colo-rectais, utilizando as classificações de NICE/WASP. O desempenho global meIhorou após a utilização contínua do diagnóstico óptico, mas não alcançou o limiar definido para a implementação da estratégia de "não ressecar".

๑ 2019 Sociedade Portuguesa de Gastrenterologia Publicado por S. Karger AG, Basel

\section{Introduction}

Colonoscopy with polyp resection has demonstrated a consistent reduction in colorectal cancer incidence [1]. However, more than $90 \%$ of the polyps detected at colonoscopy are small $(<10 \mathrm{~mm})$ or diminutive $(\leq 5 \mathrm{~mm})$ and at least half are nonneoplastic, making many polypectomies unnecessary while increasing procedure-related risks and costs [2-4]. An accurate in vivo prediction of colorectal polyp histology could help avoid unnecessary polypectomies and prevent histopathologic analysis of diminutive adenomatous polyps in order to inform the surveillance interval recommendations. These strategies, respectively defined as "do not resect" and "resect and discard," have been increasingly advocated to promote more efficient and cost-effective colonoscopies $[2,5,6]$. For safely implementation of these strategies in clinical practice, the American Society for Gastrointestinal Endoscopy (ASGE), in its Preservation and Incorporation of Valuable Endoscopic Innovations (PIVI) statement, defined the performance thresholds that need to be achieved [7].

Narrow-band imaging (NBI) is a simple "push of a button" electronic chromoendoscopy modality that uses narrow-band light filters to enhance mucosal architecture and vascular structures, allowing a real-time differentiation of histology [8]. Ex vivo studies demonstrated a short learning curve for its application [9].

The NBI International Colorectal Endoscopic (NICE) classification was developed and validated for real-time characterization of adenomas and hyperplastic polyps, with excellent performances among expert endoscopists [10]. However, it is still necessary to assess whether these can be systematically replicated in routine practice.

Although the majority of colorectal cancer develops from adenomas, almost $15-30 \%$ arise via the serrated pathway, with sessile serrated adenomas/polyps (SSP) and traditional serrated adenomas being the precursor lesions [11-14]. The Workgroup serrAted polypS and Polyposis (WASP) classification was created combining the NICE classification and the criteria for SSP characterization, allowing an in vivo differentiation of the most prevalent polyp subtypes: adenomas, hyperplastic polyps, and SSP [15]. The diagnostic performance of the WASP classification still lacks further validation, especially beyond the scope of clinical trials. In addition, a learning effect in real-time application of optical diagnosis needs to be ascertained.

We conducted an observational study evaluating the accuracy of the simultaneous application of the NICE and WASP classifications among community endoscopists with no previous experience with NBI. As a secondary aim we assessed the impact of the daily application of optical diagnosis and whether it could meet the standards for the implementation of the "do not resect" strategy.

\section{Subjects and Methods}

\section{Study Design}

An observational study was conducted among gastroenterologists from a single nonacademic oncology center (Instituto Português de Oncologia de Lisboa Francisco Gentil, Lisbon, Portugal). The study was performed during two periods: January to February 


\begin{tabular}{|lll}
\hline & Type 1 & Type 2 \\
\hline Color & same or lighter than background & $\begin{array}{l}\text { browner relative to background (verify color } \\
\text { arises from vessels) }\end{array}$ \\
\hline Vessels & $\begin{array}{l}\text { none, or isolated lacy vessels coursing across the } \\
\text { lesion }\end{array}$ & brown vessels surrounding white structures \\
\hline Surface pattern & $\begin{array}{l}\text { dark or white spots of uniform size, or homogeneous } \\
\text { absence of pattern }\end{array}$ & $\begin{array}{l}\text { oval, tubular, or branched white structures } \\
\text { surrounded by brown vessels }\end{array}$ \\
\hline Most likely pathology & hyperplastic polyp & adenoma \\
\hline
\end{tabular}

Fig. 1. NICE classification (adapted from Hewett et al. [10]).

Fig. 2. WASP classification (adapted from

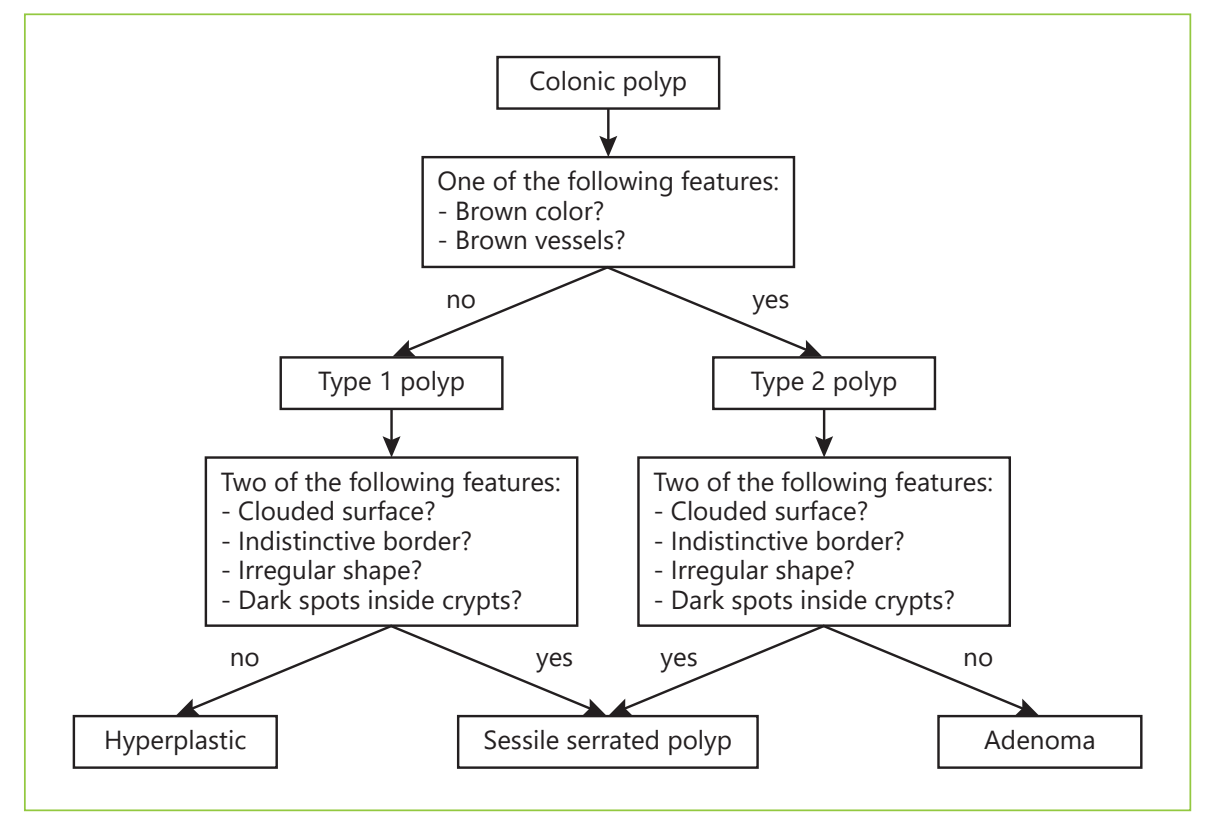
Ijspeert et al. [15]).

2016 (period 1, P1) and January to February 2017 (period 2, P2). All outpatient elective colonoscopies submitted to polypectomy and histopathologic analysis were eligible.

\section{Participants and Training}

Four trainees and nine attending physicians participated in the study. Trainees performed colonoscopies only in the presence of an attending physician. Before participation in P1, a trainee (J.C.) presented a 20-min audiovisual training based on the NICE and WASP classifications (Fig. 1,2). None of the endoscopists had previous experience with NBI. After the first period (P1) the participants were encouraged to use NBI at their own discretion on a daily basis, with no additional formal training before participation in the second period (P2).

\section{Endoscopic Equipment and Procedure}

The study took place during the routine practice of the department. All procedures were performed using colonoscopes equipped with NBI technology: Evis Exera III CF-H190 videocolonoscopes, CV-190 processors, Olympus Europe, Hamburg, Germany. The endoscopy rooms were equipped with high-definition monitors.

All colonoscopies were performed with high-definition whitelight mode, and if a polyp was detected it was further evaluated with NBI mode. Optic magnification was not used. For each detected polyp, the location, size, morphology, optical diagnosis, and level of confidence of the prediction were recorded. The location of the polyps was specified as cecum, ascending, hepatic flexure, transverse, splenic flexure, descending, sigmoid, and rectum; those in or distal to the splenic flexure were defined as left colon polyps and those proximal to the splenic flexure as right colon polyps. The polyp size was estimated by comparison to the open biopsy forceps. Polyps $\leq 5 \mathrm{~mm}$ were defined as diminutive, those $6-10 \mathrm{~mm}$ as small, and those $>10 \mathrm{~mm}$ as large. The morphology was described according to the Paris classification [16]. After NBI assessment, the optical diagnosis of each polyp was made according to the NICE and WASP classifications: hyperplastic polyps (type 1p), SSP (type 1s), 

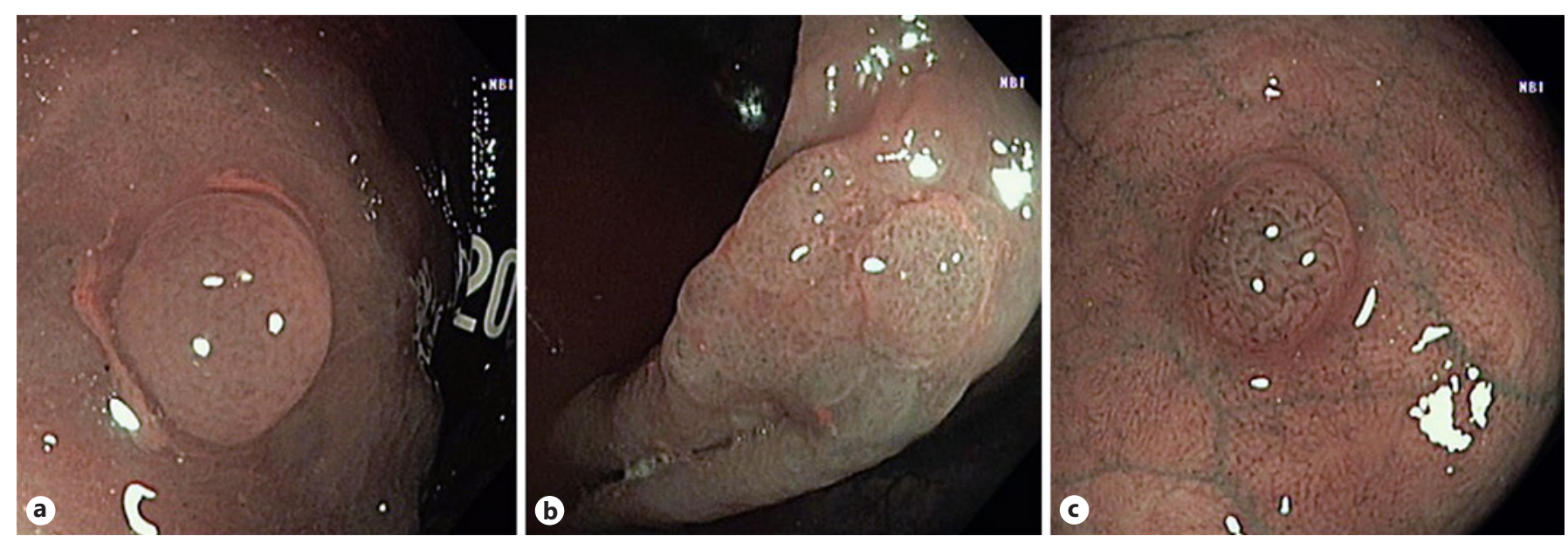

Fig. 3. Narrow-band imaging of polyps. a Hyperplastic polyp, with a lighter color than the background, no vessels, and dark uniform spots. b Sessile serrated polyp, with a clouded surface, irregular shape, and indistinctive borders. c Adenoma, browner than the background, with tubular structures surrounded by brown vessels.

Table 1. Characteristics of the polyps and level of confidence between the first (P1) and second period (P2) of the study

\begin{tabular}{|c|c|c|c|}
\hline & $\begin{array}{l}\mathrm{P} 1 \\
(n=192)\end{array}$ & $\begin{array}{l}\mathrm{P} 2 \\
(n=98)\end{array}$ & $p$ value \\
\hline \multicolumn{4}{|l|}{ Location } \\
\hline Right colon & $79(41 \%)$ & $36(37 \%)$ & \multirow{3}{*}{0.593} \\
\hline Left colon & $113(59 \%)$ & $61(62 \%)$ & \\
\hline Not specified & 0 & $1(1 \%)$ & \\
\hline \multicolumn{4}{|l|}{ Morphology } \\
\hline Pedunculated & $28(15 \%)$ & $12(12 \%)$ & \multirow{3}{*}{0.652} \\
\hline Sessile/flat & $159(83 \%)$ & $86(88 \%)$ & \\
\hline Not specified & $5(2 \%)$ & 0 & \\
\hline \multicolumn{4}{|l|}{ Size } \\
\hline Diminutive polyps $(\leq 5 \mathrm{~mm})$ & $111(58 \%)$ & $61(62 \%)$ & \multirow{3}{*}{0.766} \\
\hline Small polyps $(6-10 \mathrm{~mm})$ & $64(33 \%)$ & $29(30 \%)$ & \\
\hline Large polyps (>10 mm) & $17(9 \%)$ & $8(8 \%)$ & \\
\hline \multicolumn{4}{|l|}{ Level of confidence } \\
\hline Low & $43(22 \%)$ & $24(24 \%)$ & \multirow{2}{*}{0.800} \\
\hline High & $149(78 \%)$ & $74(76 \%)$ & \\
\hline
\end{tabular}

and adenomas (type 2) (Fig. 3). The level of confidence for each optical diagnosis was recorded as high (if the endoscopist made the optical diagnosis with a certainty $>90 \%$ ) or low [17].

\section{Histopathologic Diagnosis}

All included polyps were endoscopically removed and sent to histopathologic analysis. Pathologists blinded to the optical diagnosis assessed polyp histology, which was classified according to the WHO guidelines [18]. For study purposes, only the final histologies contemplated in the NICE/WASP classifications were included.

\section{Endpoints}

(1) To determine the overall performance (accuracy, sensitivity, specificity, positive predictive value [PPV], and negative predictive value [NPV]) of optical diagnosis among nonexpert endoscopists. (2) To evaluate the learning effect with ongoing application of optical diagnosis by comparison between P1 and P2 performances. (3) To identify predictors of performance. (4) To assess whether the endoscopists could achieve the threshold for the implementation of the "do not resect" strategy. According to the ASGE PIVI statement, diminutive rectosigmoid hyperplastic polyps can be left in place, i.e., not resected, since the real-time endoscopic technology provides an NPV $\geq 90 \%$ when used with high confidence for adenomatous histology [7].

\section{Statistical Analysis}

The diagnostic accuracy, sensitivity, specificity, PPV, NPV, positive likelihood ratio (LR+), and negative likelihood ratio (LR-) of optical diagnosis were calculated considering histopathologic diagnosis as the reference standard. The comparisons between P1 and $\mathrm{P} 2$ were done using the two-sample test for equality of proportions. 95\% CIs were calculated using the exact method.

Multilevel logistic regression was used to evaluate the factors associated with diagnostic accuracy adjusting for the possible correlation between observations within each physician (cluster). We conducted univariate and multivariable analyses, both at the polyp level, taking the accuracy of optical diagnosis of adenoma (correctly diagnosed versus not) as the dependent variable. The potential predictors tested for association were polyp morphology (pedunculated versus sessile/flat), polyp size ( $>10 \mathrm{~mm}$ versus $\leq 10 \mathrm{~mm}$ ), number of polyps removed ( $>3$ versus $\leq 3$ ), and the physicians' self-reported level of confidence in the assessment (high versus low). All tests were two-sided and we considered a significance level of $5 \%$. The analysis was done using $\mathrm{R}$ version 3.1.2 (http://www.R-project.org/). 
Table 2. Comparison of the overall accuracy of optical diagnosis between the first (P1) and second period (P2) of the study using the NICE and WASP classifications

\begin{tabular}{|c|c|c|c|c|c|c|}
\hline Overall analysis & \multicolumn{2}{|l|}{$\mathrm{P} 1$} & \multicolumn{2}{|l|}{$\mathrm{P} 2$} & $\begin{array}{l}\text { Improvement } \\
(95 \% \text { CI })\end{array}$ & $p$ value \\
\hline With high confidence & 149 & $0.79(0.72$ to 0.85$)$ & 74 & $0.91(0.81$ to 0.96$)$ & $0.11(0.01$ to 0.22$)$ & 0.053 \\
\hline Polyps $\leq 10 \mathrm{~mm}$ & 175 & $0.74(0.67$ to 0.80$)$ & 90 & $0.80(0.70$ to 0.88$)$ & $0.06(-0.05$ to 0.18$)$ & 0.327 \\
\hline
\end{tabular}

Results

\section{Study Sample}

A total of 135 colonoscopies were included and 312 polyps were detected and retrieved during both periods. Twenty-two polyps (7.05\%) had a different histology (normal colonic mucosa: 2; mucosal prolapse syndrome: 7; inflammatory alterations: 7; lymphoid aggregate: 6) from those contemplated in the NICE/WASP classifications and were excluded from the final analysis. A total of 290 polyps were analyzed: 192 polyps in $\mathrm{P} 1$ and 98 polyps in $\mathrm{P} 2 ; 193$ (66.6\%) were adenomas, 83 hyperplastic polyps (28.6\%), and 14 SSP (4.8\%).

The characteristics of the polyps are shown in Table 1. In both periods, the majority of polyps were located in the left colon (P1: 59\%; P2: 62\%), had a sessile/flat morphology (P1: 83\%; P2: 88\%) and were diminutive (P1: 58\%; P2: $62 \%)$. There was no difference in the location $(p=0.593)$, morphology $(p=0.652)$, and size of the polyps $(p=0.766)$ as well as in the level of confidence $(p=0.800)$ of the assignments between P1 and P2.

\section{Comparison of Diagnostic Accuracy}

The comparison of the overall accuracy of optical diagnosis between P1 and P2, using the NICE/WASP classifications, is shown in Table 2. The overall accuracy of optical diagnosis was 0.75 (95\% CI 0.68-0.81) in P1, with an increase to 0.82 (95\% CI 0.73-0.89) in P2, although not achieving statistical significance $(p=0.260)$. Polyps classified with a high confidence level had an overall diagnostic accuracy of 0.79 (95\% CI 0.72-0.85) in P1, increasing to 0.91 (95\% CI $0.81-0.96)$ in P2 (11\% improvement; $95 \%$ CI $1-22 \%$; $p=0.053)$.

The dichotomized accuracy between P1 and P2 to discriminate the different polyp subtypes is represented in Table 3. The accuracy of the NICE/WASP classifications to differentiate adenomas from nonadenomas was 0.78 (95\% CI 0.72-0.84) in P1 and 0.86 (95\% CI 0.77-0.92) in P2 $(p=0.164)$; assignments made with a high confidence level achieved statistical significance for the global sample (13\% improvement, 95\% CI 3-22\%; $p=0.022$ ) and also for polyps $\leq 10 \mathrm{~mm}$ (14\% improvement, $95 \%$ CI 3-24\%; $p=0.023$ ) between the two study periods.

\section{Real-Time Endoscopic Diagnosis of Adenomatous}

Histology: Predictors of Diagnostic Accuracy and PIVI Statement Performance

The sensitivity, specificity, PPV, NPV, LR+, and LRof the NICE/WASP classifications for differentiating adenomatous histology, among the two study periods, are shown in Table 4. The NICE/WASP classifications showed a sensitivity, specificity, PPV, and NPV of 79, 77, 87 , and $64 \%$ in P1, with an increase to $82,94,96$, and $72 \%$ in P2. The LR+ and LR- results also showed an increase in the overall performance of the NICE/WASP classifications from P1 to P2.

In univariate analysis the high confidence level of the assessments was the only predictor associated with accuracy for adenomatous histology (Table 5). No association could be demonstrated either for morphology, size, or number of polyps removed. Multivariable analysis confirmed the high confidence level of the predictions as the only factor independently associated with diagnostic accuracy for adenomatous histology (OR $=2.71,95 \% \mathrm{CI}$ $1.36-5.40 ; p=0.005)$.

Regarding the ASGE PIVI statement for the "not to resect" strategy, the NPV for adenomatous histology of diminutive $(\leq 5 \mathrm{~mm})$ rectosigmoid polyps for classifications made with a high confidence level was $81 \%$ (95\% CI $64-93 \% ; n=49)$ and $80 \%(95 \%$ CI $59-93 \% ; n=35)$ in P1 and $\mathrm{P} 2$, respectively. 
Table 3. Comparison of dichotomized accuracy of optical diagnosis of adenoma and serrated polyps before (P1) and after routine application of narrow-band imaging (P2)

\begin{tabular}{|c|c|c|c|c|}
\hline & $\begin{array}{l}\text { Accuracy P1 } \\
(95 \% \text { CI })\end{array}$ & $\begin{array}{l}\text { Accuracy P2 } \\
(95 \% \mathrm{CI})\end{array}$ & $\begin{array}{l}\text { Improvement } \\
(95 \% \mathrm{CI})\end{array}$ & $p$ value \\
\hline \multicolumn{5}{|c|}{ Adenoma versus nonadenoma } \\
\hline All polyps & $0.78(0.72$ to 0.84$)$ & $0.86(0.77$ to 0.92$)$ & $0.08(-0.02$ to 0.17$)$ & 0.164 \\
\hline With high confidence & $0.81(0.73$ to 0.87$)$ & $0.93(0.85$ to 0.98$)$ & $0.13(0.03$ to 0.22$)$ & 0.022 \\
\hline Polyps $\leq 10 \mathrm{~mm}$ & $0.77(0.70$ to 0.83$)$ & $0.84(0.75$ to 0.91$)$ & $0.08(-0.03$ to 0.18$)$ & 0.181 \\
\hline With high confidence & $0.79(0.74$ to 0.86$)$ & $0.93(0.84$ to 0.98$)$ & $0.14(0.03$ to 0.24$)$ & 0.023 \\
\hline \multicolumn{5}{|c|}{ Sessile serrated polyps versus nonsessile serrated polyps } \\
\hline All polyps & $0.92(0.87$ to 0.95$)$ & $0.92(0.85$ to 0.96$)$ & $0.00(-0.07$ to 0.07$)$ & 1.000 \\
\hline With high confidence & $0.95(0.91$ to 0.98$)$ & $0.97(0.91$ to 1.00$)$ & $0.02(-0.04$ to 0.08$)$ & 0.725 \\
\hline Polyps $\leq 10 \mathrm{~mm}$ & $0.91(0.86$ to 0.95$)$ & $0.91(0.83$ to 0.96$)$ & $0.00(-0.08$ to 0.07$)$ & 1.000 \\
\hline With high confidence & 0.95 (0.90 to 0.98$)$ & $0.97(0.90$ to 1.00$)$ & $0.02(-0.05$ to 0.08$)$ & 0.875 \\
\hline \multicolumn{5}{|c|}{ Hyperplastic polyps versus nonhyperplastic polyps } \\
\hline All polyps & $0.81(0.74$ to 0.86$)$ & $0.86(0.77$ to 0.92$)$ & $0.05(-0.05$ to 0.15$)$ & 0.373 \\
\hline With high confidence & $0.83(0.76$ to 0.89$)$ & $0.91(0.81$ to 0.96$)$ & $0.07(-0.03$ to 0.17$)$ & 0.206 \\
\hline Polyps $\leq 10 \mathrm{~mm}$ & $0.79(0.73$ to 0.85$)$ & $0.84(0.75$ to 0.91$)$ & $0.05(-0.05$ to 0.15$)$ & 0.411 \\
\hline With high confidence & $0.82(0.74$ to 0.88$)$ & $0.90(0.80$ to 0.96$)$ & $0.08(-0.03$ to 0.19$)$ & 0.218 \\
\hline
\end{tabular}

Table 4. Performance in differentiating adenomatous histology using the NICE/WASP classifications (overall and with high confidence level)

\begin{tabular}{|c|c|c|c|c|}
\hline & \multicolumn{2}{|l|}{ Overall analysis } & \multicolumn{2}{|c|}{ With high confidence } \\
\hline & $\mathrm{P} 1(n=192)$ & $\mathrm{P} 2(n=98)$ & $\mathrm{P} 1(n=149)$ & $\mathrm{P} 2(n=74)$ \\
\hline Sensitivity (95\% CI), \% & $79(71$ to 86$)$ & $82(70$ to 90$)$ & $82(73$ to 88$)$ & 90 (78 to 97$)$ \\
\hline Specificity (95\% CI), \% & $77(64$ to 86$)$ & 94 (80 to 99$)$ & $78(62$ to 89$)$ & $100(80$ to 100$)$ \\
\hline Positive predictive value (95\% CI), \% & $87(80$ to 93$)$ & $96(87$ to 100$)$ & $91(83$ to 96$)$ & $100(88$ to 100$)$ \\
\hline Negative predictive value (95\% CI), \% & $64(53$ to 75$)$ & $72(56$ to 85$)$ & $61(46$ to 74$)$ & $83(65$ to 94$)$ \\
\hline Positive likelihood ratio (95\% CI) & $3.37(2.14$ to 5.29$)$ & $13.45(3.49$ to 51.81$)$ & $3.63(2.03$ to 6.49$)$ & $+\operatorname{Inf}$ \\
\hline Negative likelihood ratio (95\% CI) & $0.28(0.19$ to 0.40$)$ & $0.20(0.12$ to 0.33$)$ & $0.24(0.15$ to 0.36$)$ & $0.10(0.4$ to 0.23$)$ \\
\hline
\end{tabular}

\section{Discussion and Conclusion}

The current study is one of the few studies reporting on the real-time optical diagnosis of colorectal polyps simultaneously using the NICE and WASP classifications among community endoscopists with no previous experience in NBI. The overall diagnostic accuracy before previous experience with NBI was moderate $(0.75,95 \%$ CI $0.68-0.81)$. Studies conducted in an academic setting revealed a higher accuracy with continuing NBI experience $[17,19-21]$. In a nonacademic setting the real-time diag- nosis has demonstrated divergent results, ranging from moderate to high diagnostic performances [22-27]. Our results were comparable to those reported by Kuiper et al. [25], who conducted a prospective trial in two nonacademic centers, evaluating optical diagnosis using highresolution endoscopy or NBI, achieving an overall sensitivity, specificity, and accuracy of 77.0, 78.8, and 77.9\%, respectively. However, contrary to our study, the participating endoscopists had former contact with NBI, including participation in two previous studies evaluating NBI application. Vu et al. [24] also reported moderate diag- 
Table 5. Univariate and multivariable analyses of the factors associated with diagnostic accuracy in differentiating adenomatous histology using the NICE/WASP classifications

\begin{tabular}{|c|c|c|c|c|c|c|}
\hline & \multicolumn{3}{|c|}{ Univariate analysis } & \multicolumn{3}{|c|}{ Multivariable analysis } \\
\hline & OR & $95 \% \mathrm{CI}$ & $p$ value & OR & $95 \% \mathrm{CI}$ & $p$ value \\
\hline \multicolumn{7}{|c|}{ Polyp morphology } \\
\hline Sessile/flat & 1 & & & 1 & & \\
\hline Pedunculated & 1.81 & 0.60 to 5.44 & 0.294 & 1.00 & 0.31 to 3.22 & 0.995 \\
\hline \multicolumn{7}{|l|}{ Polyp size } \\
\hline$\leq 10 \mathrm{~mm}$ & 1 & & & 1 & & \\
\hline$>10 \mathrm{~mm}$ & 6.24 & 0.82 to 47.30 & 0.076 & 4.98 & 0.63 to 39.49 & 0.129 \\
\hline \multicolumn{7}{|c|}{ Polyps removed, $n$} \\
\hline$\leq 3$ & 1 & & & 1 & & \\
\hline$>3$ & 1.24 & 0.65 to 2.36 & 0.511 & 1.21 & 0.61 to 2.40 & 0.580 \\
\hline \multicolumn{7}{|l|}{ Confidence } \\
\hline Low $(<90 \%)$ & 1 & & & 1 & & \\
\hline High $(>90 \%)$ & 2.90 & 1.52 to 5.53 & 0.001 & 2.71 & 1.36 to 5.40 & 0.005 \\
\hline
\end{tabular}

nostic performance results. The study included both academic and community gastroenterologists, reporting an overall accuracy of histological predictions made with a high confidence of $77.1 \%$; academic and community gastroenterologists achieved an accuracy of 76.3 and $80.2 \%$, respectively ( $p=0.38$ ). Rees et al. [23] evaluated the implementation of the NICE classification for optical diagnosis and also reported disappointing performance results, with an accuracy of adenoma characterization of $83 \%$ and a test sensitivity of need for surveillance of $73 \%$. The authors concluded that NBI optical diagnosis is not accurate enough to replace histology in routine clinical practice. In our study, simultaneously analysis with the NICE and WASP classifications may have affected the overall results, making the comparison with other previous studies difficult, since the majority of them only evaluated the differentiation between adenomas and hyperplastic polyps.

In the second period of the study, the endoscopists attained a better accuracy $(0.82,95 \%$ CI $0.73-0.89)$, but this difference did not achieve statistical significance $(p=$ 0.260 ). In both periods, the NPV for adenomatous histology was $<90 \%$, failing to reach the ASGE PIVI benchmark and precluding the implementation of the "do not resect" policy. Studies have demonstrated a short learning curve for accurate characterization of colorectal lesions with NBI, with teaching modules of only 20 min being enough to achieve high accuracies [28-30]. However, in a realtime situation the learning curve of NBI might be longer [31]. Our results are in agreement with this assumption, showing that a continuous implementation of NBI in the characterization of colorectal lesions, although achieving an improvement over time, especially for the subset of predictions made with a high confidence level, the overall learning effect is below expectations and it is not enough to implement the "do not resect" strategy in clinical practice. East et al. [32] and Rastogi et al. [20] also found no learning curve effect in real-time optical diagnosis by endoscopists experienced with the NBI technology. Ladabaum et al. [22] developed one of the few studies to evaluate the effect of an intensive in vivo training module among community gastroenterologists with no previous experience with NBI, revealing the absence of a clear pattern of early learning or later stabilization of performance at a higher level. Contrary to these results, there are several studies showing the positive impact of standardized and continued training programs [27, 33-35]. McGill et al. [34] demonstrated high diagnostic performance, with an NPV of $95.4 \%$ for diminutive rectosigmoid polyps, among endoscopists who completed a computer-based module, followed by ten real-time colonoscopies. Further studies are necessary to access the best learning model and to definitely ascertain whether optical diagnosis is feasible among community endoscopists.

Although the NICE classification has been demonstrated to be easy to apply and feasible to implement, it has been criticized for omitting SSP characterization [36, 37]. Kumar et al. [38] demonstrated that SSP share an overlap of the NICE features usually found in both hyperplastic polyps and adenomas, which may contribute to 
missing SSP and to an erroneous classification of SSP with malignant potential as simple benign hyperplastic polyps $[37,38]$. Therefore, it has been advocated that the "resect and discard" and "do not resect" policies could only be safely implemented with the proper differentiation of all polyp subtypes, namely SSP. A meta-analysis published in 2016 demonstrated a sensitivity of $60 \%$ for NBI to discriminate SSP from nonneoplastic lesions, showing the potential of this technology for the optical diagnosis of SSP [39]. Ijspeert et al. [15] developed and validated, with still images, the WASP classification to endoscopically differentiate hyperplastic polyps, adenomas, and SSP, achieving an overall accuracy for optical diagnosis of 0.63 , which improved to 0.79 after training, with sustainable results after 6 months. The optical diagnosis of SSP had an accuracy of 0.74 and 0.86 before and after training, respectively. In our study, there was no improvement in the accuracy to differentiate SSP between both periods, however the initial performance was already good $(0.92,95 \%$ CI $0.87-0.95)$. The accuracy to differentiate adenomatous from nonadenomatous histology significantly improved over time for the predictions made with a high confidence level ( 0.81 and 0.93 in P1 and P2, respectively; $p=0.022$ ). This result suggests that endoscopic recognition of adenomas may be easier in comparison to the other polyp subtypes. The darker color and brown vessels may facilitate their recognition. Indeed, previous studies demonstrated that microvascular assessment is associated with a short learning curve $[31,32,40]$. Vleugels et al. [33], in a recently published study, were the first to report the real-time application of optical diagnosis with the WASP classification, with outstanding results of performance, achieving a global NPV for rectosigmoid neoplastic lesions of $90.8 \%$, with a surveillance interval agreement of $95.4 \%$. However, contrary to our study, they only included endoscopists who qualified after an intensive and structured training protocol. The intensive selection of the endoscopists may have limited the generalizability of their results but may suggest, once again, the importance of motivation, interest, continued training, and a mandatory accreditation process to ensure adequate performance $[22,27,33,34,41]$.

Our study has important strengths, but also limitations, that are important to highlight. As mentioned before, this is one of the few studies simultaneous evaluating the application of the NICE and WASP classifications for real-time colorectal lesion characterization in routine clinical practice. Our results may be more representative than the results of previous studies of routine clinical practice, with all the constrains of daily "real-world" situ- ations and with the inclusion of all polyp categories. This study was also enriched due to the evaluation of the learning effect of continuous application of optical diagnosis. However, as a limitation, the unicentric design, the limited number of polyps included in both study periods, with a disproportional number of polyps in each period (P1: $n=192 ; \mathrm{P} 2: n=98)$, might have compromised the statistical analysis. Another potential limitation of this study is the fact that all outpatient elective colonoscopies were eligible, namely hereditary colorectal syndromes/ polyposis or previous colorectal cancer. However, there is no reason to assume that the polyps of this group of patients have a different phenotype compared to the sporadic ones, precluding data extrapolation to the general population. Additionally, the training process solely based on a 20-min audiovisual session as well as the lack of continuous feedback and a structured training program may have compromised the final results of performance. Finally, it would be important to analyze not only the "do not resect" policy, but also the "resect and discard" strategy, in order to fully evaluate the ability of nonexpert endoscopists to implement optical diagnosis in daily practice.

In conclusion, nonexpert community endoscopists achieved moderate accuracy for real-time optical diagnosis of colorectal lesions with the NICE and WASP classifications, with slight improvement over time. The ASGE PIVI threshold for the implementation of the "do not resect" strategy was not accomplished, precluding its widespread outside an academic setting. Therefore, despite encouraging preliminary results, further structured and formal training with periodic reassessment of endoscopists' performances is necessary before its widespread use as a standard of care in routine practice.

\section{Acknowledgments}

The authors are grateful to the staff members of the Department of Gastroenterology of the Instituto Português de Oncologia de Lisboa Francisco Gentil for their contribution and support during the study period.

\section{Statement of Ethics}

The study was conducted in accordance with the ethical standards of the institutional research committee and with the 1964 Helsinki declaration and its later amendments or comparable ethical standards. The department board and all the participating gastroenterologists approved the study protocol. Based on the methodology described by Ladabaum et al. [22] and according to the 
Institutional Ethics Board it was decided that the study did not require formal informed consent from the patients since their care would not be affected or modified by the study.

\section{Disclosure Statement}

The authors have no financial relationships or conflicts of interest relevant to this article to disclose.

\section{Author Contributions}

J. Castela is responsible for study concept and design, data acquisition, analysis, and interpretation, and preparation and writing of the manuscript. S. Mão de Ferro, I. Rosa, P. Lage, S. Ferreira, J. Pereira Silva, J. Cortez Pinto, R. Vale Rodrigues, J. Moleiro, I. Claro, and A. Dias Pereira are responsible for study concept and design, data acquisition, and critical manuscript revision. S. Esteves is responsible for statistical analysis, data interpretation, and critical manuscript revision. All authors approved the final draft.

\section{References}

1 Zauber AG, Winawer SJ, O'Brien MJ, Lansdorp-Vogelaar I, van Ballegooijen M, Hankey $\mathrm{BF}$, et al. Colonoscopic polypectomy and long-term prevention of colorectal-cancer deaths. N Engl J Med. 2012 Feb;366(8):68796.

2 Lieberman D, Moravec M, Holub J, Michaels L, Eisen G. Polyp size and advanced histology in patients undergoing colonoscopy screening: implications for CT colonography. Gastroenterology. 2008 Oct;135(4):1100-5.

3 Rex DK, Overhiser AJ, Chen SC, Cummings OW, Ulbright TM. Estimation of impact of American College of Radiology recommendations on CT colonography reporting for resection of high-risk adenoma findings. Am J Gastroenterol. 2009 Jan;104(1):149-53.

4 Butterly LF, Chase MP, Pohl H, Fiarman GS. Prevalence of clinically important histology in small adenomas. Clin Gastroenterol Hepatol. 2006 Mar;4(3):343-8.

5 Regula J, Rupinski M, Kraszewska E, Polkowski M, Pachlewski J, Orlowska J, et al. Colonoscopy in colorectal-cancer screening for detection of advanced neoplasia. N Engl J Med. 2006 Nov;355(18):1863-72.

6 Hassan C, Pickhardt PJ, Rex DK. A resect and discard strategy would improve cost-effectiveness of colorectal cancer screening. Clin Gastroenterol Hepatol. 2010 Oct;8(10):8659, 869.e1-3.

7 Rex DK, Kahi C, O’Brien M, Levin TR, Pohl $\mathrm{H}$, Rastogi A, et al. The American Society for Gastrointestinal Endoscopy PIVI (Preservation and Incorporation of Valuable Endoscopic Innovations) on real-time endoscopic assessment of the histology of diminutive colorectal polyps. Gastrointest Endosc. 2011 Mar;73(3):419-22.

8 Song LM, Adler DG, Conway JD, Diehl DL, Farraye FA, Kantsevoy SV, et al.; ASGE Technology Committee. Narrow band imaging and multiband imaging. Gastrointest Endosc. 2008 Apr;67(4):581-9.

9 Patel SG, Rastogi A, Austin G, Hall M, Siller BA, Berman K, et al. Gastroenterology trainees can easily learn histologic characterization of diminutive colorectal polyps with narrow band imaging. Clin Gastroenterol Hepatol. 2013 Aug;11(8):997-1003.e1.
10 Hewett DG, Kaltenbach T, Sano Y, Tanaka S, Saunders BP, Ponchon T, et al. Validation of a simple classification system for endoscopic diagnosis of small colorectal polyps using narrow-band imaging. Gastroenterology. 2012 Sep;143(3):599-607.e1.

11 Vogelstein B, Fearon ER, Hamilton SR, Kern SE, Preisinger AC, Leppert M, et al. Genetic alterations during colorectal-tumor development. N Engl J Med. 1988 Sep;319(9):525-32.

12 Snover DC. Update on the serrated pathway to colorectal carcinoma. Hum Pathol. 2011 Jan;42(1):1-10.

13 Leggett B, Whitehall V. Role of the serrated pathway in colorectal cancer pathogenesis. Gastroenterology. 2010 Jun; 138(6):2088100.

14 De Sousa E Melo F, Wang X, Jansen M, Fessler E, Trinh A, de Rooij LP, et al. Poor-prognosis colon cancer is defined by a molecularly distinct subtype and develops from serrated precursor lesions. Nat Med. 2013 May;19(5): 614-8.

15 Ijspeert JE, Bastiaansen BA, van Leerdam ME, Meijer GA, van Eeden S, Sanduleanu S, et al.; Dutch Workgroup serrAted polypS \& Polyposis (WASP). Development and validation of the WASP classification system for optical diagnosis of adenomas, hyperplastic polyps and sessile serrated adenomas/polyps. Gut. 2016 Jun;65(6):963-70.

16 The Paris endoscopic classification of superficial neoplastic lesions: esophagus, stomach, and colon: November 30 to December 1 , 2002. Gastrointest Endosc. 2003 Dec;58(6 Suppl):S3-43.

17 Ignjatovic A, East JE, Suzuki N, Vance M, Guenther T, Saunders BP. Optical diagnosis of small colorectal polyps at routine colonoscopy (Detect InSpect ChAracterise Resect and Discard; DISCARD trial): a prospective cohort study. Lancet Oncol. 2009 Dec;10(12): 1171-8.

18 Bosman FT, Hruban RH, Theise ND. WHO Classification of Tumours of the Digestive System. Lyon: IARC Press; 2010.

19 Rex DK. Narrow-band imaging without optical magnification for histologic analysis of colorectal polyps. Gastroenterology. 2009 Apr;136(4):1174-81.
20 Rastogi A, Keighley J, Singh V, Callahan P, Bansal A, Wani S, et al. High accuracy of narrow band imaging without magnification for the real-time characterization of polyp histology and its comparison with high-definition white light colonoscopy: a prospective study. Am J Gastroenterol. 2009 Oct;104(10):242230.

21 Pohl H, Bensen SP, Toor A, Gordon SR, Levy LC, Anderson PB, et al. Quality of optical diagnosis of diminutive polyps and associated factors. Endoscopy. 2016 Sep;48(9):817-22.

22 Ladabaum U, Fioritto A, Mitani A, Desai M, Kim JP, Rex DK, et al. Real-time optical biopsy of colon polyps with narrow band imaging in community practice does not yet meet key thresholds for clinical decisions. Gastroenterology. 2013 Jan;144(1):81-91.

23 Rees CJ, Rajasekhar PT, Wilson A, Close $\mathrm{H}$, Rutter MD, Saunders BP, et al. Narrow band imaging optical diagnosis of small colorectal polyps in routine clinical practice: the Detect Inspect Characterise Resect and Discard 2 (DISCARD 2) study. Gut. 2017 May;66(5): 887-95.

24 Vu HT, Sayuk GS, Hollander TG, Clebanoff J, Edmundowicz SA, Gyawali CP, et al. Resect and discard approach to colon polyps: realworld applicability among academic and community gastroenterologists. Dig Dis Sci. $2015 \mathrm{Feb} ; 60(2): 502-8$.

25 Kuiper T, Marsman WA, Jansen JM, van Soest EJ, Haan YC, Bakker GJ, et al. Accuracy for optical diagnosis of small colorectal polyps in nonacademic settings. Clin Gastroenterol Hepatol. 2012 Sep;10(9):1016-20; quiz e79.

26 Seref Köksal A, Yıldız H, Taşkıran I, Turhan $\mathrm{N}$, Oztaş E, Torun S, et al. Low magnification narrow band imaging by inexperienced endoscopists has a high accuracy in differentiation of colon polyp histology. Clin Res Hepatol Gastroenterol. 2014 Dec;38(6):763-9.

27 Patel SG, Schoenfeld P, Kim HM, Ward EK, Bansal A, Kim Y, et al. Real-Time Characterization of Diminutive Colorectal Polyp Histology Using Narrow-Band Imaging: Implications for the Resect and Discard Strategy. Gastroenterology. 2016 Feb;150(2):406-18. 
28 Higashi R, Uraoka T, Kato J, Kuwaki K, Ishikawa S, Saito Y, et al. Diagnostic accuracy of narrow-band imaging and pit pattern analysis significantly improved for less-experienced endoscopists after an expanded training program. Gastrointest Endosc. 2010 Jul; 72(1):127-35.

29 Ignjatovic A, Thomas-Gibson S, East JE, Haycock A, Bassett P, Bhandari P, et al. Development and validation of a training module on the use of narrow-band imaging in differentiation of small adenomas from hyperplastic colorectal polyps. Gastrointest Endosc. 2011 Jan;73(1):128-33.

30 Raghavendra M, Hewett DG, Rex DK. Differentiating adenomas from hyperplastic colorectal polyps: narrow-band imaging can be learned in 20 minutes. Gastrointest Endosc. 2010 Sep;72(3):572-6.

31 Rogart JN, Jain D, Siddiqui UD, Oren T, Lim J, Jamidar P, et al. Narrow-band imaging without high magnification to differentiate polyps during real-time colonoscopy: improvement with experience. Gastrointest Endosc. 2008 Dec;68(6):1136-45.

32 East JE, Suzuki N, Bassett P, Stavrinidis M, Thomas HJ, Guenther T, et al. Narrow band imaging with magnification for the characterization of small and diminutive colonic polyps: pit pattern and vascular pattern intensity. Endoscopy. 2008 Oct;40(10):811-7.
33 Vleugels JLA, Dijkgraaf MGW, Hazewinkel Y, Wanders LK, Fockens P, Dekker E, et al.; DISCOUNT Study Group. Effects of training and feedback on accuracy of predicting rectosigmoid neoplastic lesions and selection of surveillance intervals by endoscopists performing optical diagnosis of diminutive polyps. Gastroenterology. 2018 May; 154(6): 1682-93.e1.

34 McGill SK, Soetikno R, Rastogi A, Rouse RV, Sato T, Bansal A, et al. Endoscopists can sustain high performance for the optical diagnosis of colorectal polyps following standardized and continued training. Endoscopy. 2015 Mar;47(3):200-6

35 Khan T, Cinnor B, Gupta N, Hosford L, Bansal A, Olyaee MS, et al. Didactic training vs. computer-based self-learning in the prediction of diminutive colon polyp histology by trainees: a randomized controlled study. Endoscopy. 2017 Dec;49(12):1243-50.

36 Wallace MB. Not so NICE to be serrated. Gastrointest Endosc. 2013 Dec;78(6):910-1.
37 Singh A, Konda VJ, Siddiqui UD. The not so NICE classification. Gastrointest Endosc. 2014 Jun;79(6):1030-1.

38 Kumar S, Fioritto A, Mitani A, Desai M, Gunaratnam N, Ladabaum U. Optical biopsy of sessile serrated adenomas: do these lesions resemble hyperplastic polyps under narrowband imaging? Gastrointest Endosc. 2013 Dec;78(6):902-9.

39 Parikh ND, Chaptini L, Njei B, Laine L. Diagnosis of sessile serrated adenomas/polyps with image-enhanced endoscopy: a systematic review and meta-analysis. Endoscopy. 2016 Aug;48(8):731-9.

40 Rastogi A, Pondugula K, Bansal A, Wani S, Keighley J, Sugar J, et al. Recognition of surface mucosal and vascular patterns of colon polyps by using narrow-band imaging: interobserver and intraobserver agreement and prediction of polyp histology. Gastrointest Endosc. 2009 Mar;69(3 Pt 2):716-22.

41 Klare P, Haller B, Wormbt S, Nötzel E, Hartmann D, Albert J, et al. Narrow-band imaging vs. high definition white light for optical diagnosis of small colorectal polyps: a randomized multicenter trial. Endoscopy. 2016 Oct; 48(10):909-15. 